\title{
Irradiation effects in nanostructured FeCrAl oxide dispersion strengthened steel
}

\author{
Asta Richter, Chun-Liang Chen, Reinhard Kögler, Georg Talut
}

Abstract

Nanostructured ferritic oxide dispersion strengthened (ODS) alloy is an ideal candidate for fission/fusion power plant materials, particularly in the use of a first-wall and blanket structure of a next generation reactor. These steels usually contain a high density of Y-Al-O nanoparticles, high dislocation densities and fine grains. The material contains nanoparticles with an average diameter of $21 \mathrm{~nm}$. Irradiation of these alloys was performed with a dual beam irradiation of $2.5 \mathrm{MeV} \mathrm{Fe}^{+} / 31 \mathrm{dpa}$ and $350 \mathrm{keV}$ $\mathrm{He}^{+} / 18$ appm/dpa. Irradiation causes atomic displacements resulting in vacancy and self-interstitial lattice defects and dislocation loops. Additionally to structural changes, the effect of the irradiation generated defects on the mechanical properties of the ODS is investigated by nanoindentation. A clear hardness increase in the irradiated area is observed, which reaches a maximum at a close surface region. This feature is attributed to synergistic effects between the displacement damage and $\mathrm{He}$ implantation resulting in He filled vacancies.

\section{Zusammenfassung}

Ferritische Legierungen mit nanodispersen Oxidpartikeln zur Härtesteigerung sind ein geeignetes Material für Behälter und Ummantelungsstrukturen in modernen Fusions- und Kernspaltungsanlagen. Diese Stähle haben eine hohe Dichte von Y-Al-O Nanoteilchen mit einem mittleren Durchmesser von $21 \mathrm{~nm}$, eine hohe Versetzungsdichte und besitzen eine feine Kornstruktur. Bestrahlungsexperimente wurden mit einer ZweiStrahl-lonen-Quelle mit Eisen $2.5 \mathrm{MeV} \mathrm{Fe}^{+} / 31 \mathrm{dpa}$ und Helium 350 keV He+/18 appm/dpa durchgeführt. Die Bestrahlung erzeugt atomare Defekte mit Leerstellen und Zwischengitterdefekten sowie Versetzungsschleifen. Zusätzlich zu den mikro-strukturellen Modifikationen wurde die Änderung der mechanischen Eigenschaften mit der Bestrahlung untersucht. Insbesondere im oberflächennahen Bereich führt die lonenbestrahlung zu einer klaren Härtesteigerung. Dieses Verhalten wird mit einem synergetischen Modell zur Erzeugung atomarer Strahlendefekte und der Bildung von mit Helium gefüllten Leerstellen diskutiert.

\section{Introduction}

Advanced fission and fusion reactor service conditions are characterized by a combination of high temperatures and intense neutron radiation fields (Fig. 1). The study of effects of a combination of high levels of He and irradiation damage on the mechanical properties of reactor steels is a very important issue in the development of new reactor types [Zinkle et al. 2000, Yamamoto et al. 2007]. The production of 10-15 app$\mathrm{mHe} / \mathrm{dpa}$ in fusion reactors is about one order of magnitude higher than in the case of fission [Baluc 2006]. Atoms will be displaced from their lattice position creating large excess concentrations of vacancy and selfinterstitial atom defects, typically characterized by the neutron dose unit of displacement per atom (dpa). Helium is a transmutation product gas in nuclear reac-

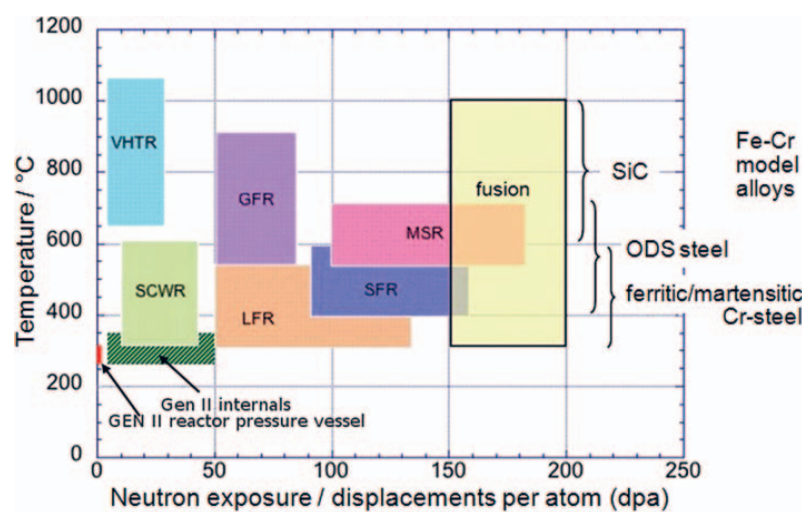

VHTR: Very high temperature reactor; SCWR: Super critical water reactor; GFR: Gas fast reactor; LFR: Lead fast reactor; SFR: Sodium fast reactor; MSR: Molten salt reactor

Fig. 1: Generation IV nuclear reactor concepts with their operation temperatures and neutron exposure. Several suitable materials for operation conditions are indicated. (S. J. Zinkle, OECD-NEA Workshop on Structural Materials for Innovative Nuclear Energy Systems, Karlsruhe, Germany, June 2001) 
tors, the concentration of which is measured in atom parts per million (appm). Helium is insoluble in steel and precipitates in gas bubbles, that are formation sites for both growing voids and grain boundary creep activities. Nuclear transmutations also change the elemental alloy composition and produce radionuclides with a wide spectrum of decay times, but will not be considered in this paper.

Advanced reactors do not demand only novel fuel forms. They also call for novel structural materials. Standard strategies for toughening materials for hightemperature applications appear unlikely to offer much help for use in nuclear reactors, where intense radiation can make materials unstable [Duffy 2010, Guerin et al. 2009, Baluc 2006]. PM 2000 is an iron-based oxide dispersion strengthened steel alloy, which possesses excellent high-temperature strength and is a promising candidate for high-temperature structural material applications, such as advanced fission/fusion power plants or hydrogen combustion energy cells.

The effect of irradiation on ODS alloys has been an important issue and stimulated worldwide investigations in the last decade [Odette et al. 2008, Pouchon et al. 2010, Kishimoto et al. 2007, Yamamoto et al. 2007]. Displacement damage drives complex microstructural and microchemical evolutions and undergoes interactions with helium. In order to understand the irradia- tion behavior of PM2000, high resolution transmission electron microscopy (HRTEM) investigations and nanoindentation experiments are performed. These are suitable methods to find potential structural changes, which can be compared with measurements of the mechanical properties in a thin surface layer damaged by irradiation.

\section{Experimental procedures}

\subsection{Materials production and processing}

Oxide dispersion strengthened alloys such as PM2000, MA956 and ODS $\mathrm{Fe}_{3} \mathrm{Al}$ are Fe-based alumina forming alloys with the additions of mainly $\mathrm{Y}_{2} \mathrm{O}_{3}$ oxide ( $\left.0.5 \mathrm{wt} \%\right)$ for mechanical strengthening. The alloys also contain Ti ( 0.5wt \%) which is added as a sink for impurities such as S, N and O. The sample studied was a hot-rolled sheet of PM2000 which is manufactured using the mechanical alloying process in a high-energy ball mill in which powders of the $73.5 \mathrm{wt} \%$ Fe master alloy plus 20 $w \mathrm{t} \% \mathrm{Cr}, 5.5 \mathrm{wt} \% \mathrm{Al}, 0.5 \mathrm{wt} \% \mathrm{Ti}$, and $0.5 \mathrm{wt} \% \mathrm{Y}_{2} \mathrm{O}_{3}$ are mixed together (Fig. 2). A process control agent (usually an organic agent) is added to the powder mixture during milling to reduce cold welding between particles, especially when the powder mix involves a substantial fraction of a ductile component. The next step is con-

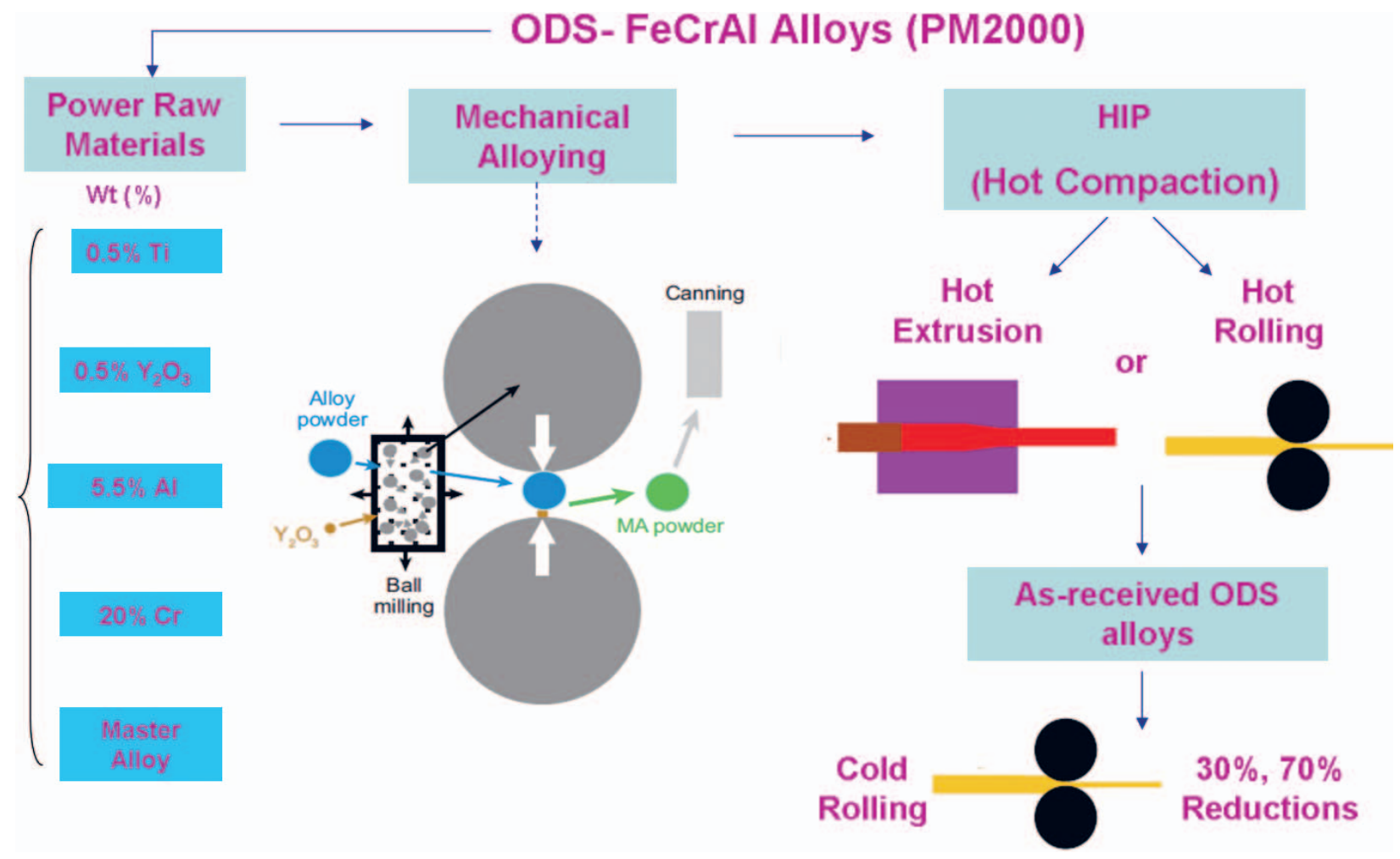

Fig. 2: Composition, mechanical alloying principle and processing of ODS PM2000 steel. 
solidation by extrusion or by means of hot compaction and then the extruded alloy is hot or cold rolled. After that, the consolidated ODS steel was annealed at 1050 ${ }^{\circ} \mathrm{C}$ for 1 hour for thermal stabilization.

PM2000 ODS alloys contain nano-scale, uniformly dispersed $\mathrm{Y}-\mathrm{Al}$ oxide particles in a $\mathrm{Fe}-\mathrm{Cr}-\mathrm{Al}$ matrix, which inhibit dislocation movement and therefore retard the recovery and re-crystallization process, where re-crystallization occurs at exceptionally high temperatures, in the order of 0.9 of the melting temperature. Although the high aluminum content can be disadvantageous because of the high activation potential for fusion applications, the formation of the $\mathrm{Al}_{2} \mathrm{O}_{3}$ layer on the surface provides superior oxidation and corrosion resistance.

\subsection{Irradiation}

Since direct neutron irradiation experiments are limited in terms of a variation of parameters such as fluence and temperature and are also very time consuming and produce highly reactive material, ion irradiation is often performed as a substitute for the true reactor conditions. Our ODS samples were irradiated in the dual beam implantation chamber (DB) at FZD Rossendorf, Center for Application of Ion Beams in Materials Research [Kaschny et al. 2005]. The facility allows materials to be implanted using two ion beams simultaneously. The sample is located at the $45^{\circ}$ cross point of two beam lines, one from a single-ended HVEE $500 \mathrm{kV}$ ion implanter and the other from a HVEE 3MV Tandetron accelerator. Each beam line is equipped with independent ion fluence and current control. The special design of the beam sweeping system enables both ion beams to scan the target surface simultaneously in synchronous mode, i.e. both ion spots are kept at coincident positions over the target. The self-ion irradiation with $\mathrm{Fe}^{+}$ions for steel, was selected to simulate the effects of a neuron induced collision cascade. The $\mathrm{Fe}^{+}$ion beam causes the radiation damage and the $\mathrm{He}^{+}$ion beam provides the source of He to model the agglomeration similar to that produced by the nuclear reaction. The $\mathrm{Fe}^{+}$ions in the dual-beam facility were implanted with an energy of $2.5 \mathrm{MeV}$ and $31 \mathrm{dpa}$ in the ODS PM2000 sample. The energy of the $\mathrm{He}^{+}$ions in the dual-beam irradiation is adapted in such a way that the maximum of the implanted $\mathrm{He}^{+}$ions appears at the same depth as that of the $\mathrm{Fe}^{+}$ions. Thus, the energy of the $\mathrm{He}^{+}$ions was set at $350 \mathrm{keV}$. With a fluence of $1.4 \times 10^{15}$ ions $/ \mathrm{cm}^{2}$ the $\mathrm{He}^{+} / \mathrm{dpa}$ ratio is $18 \mathrm{appm} / \mathrm{dpa}$.

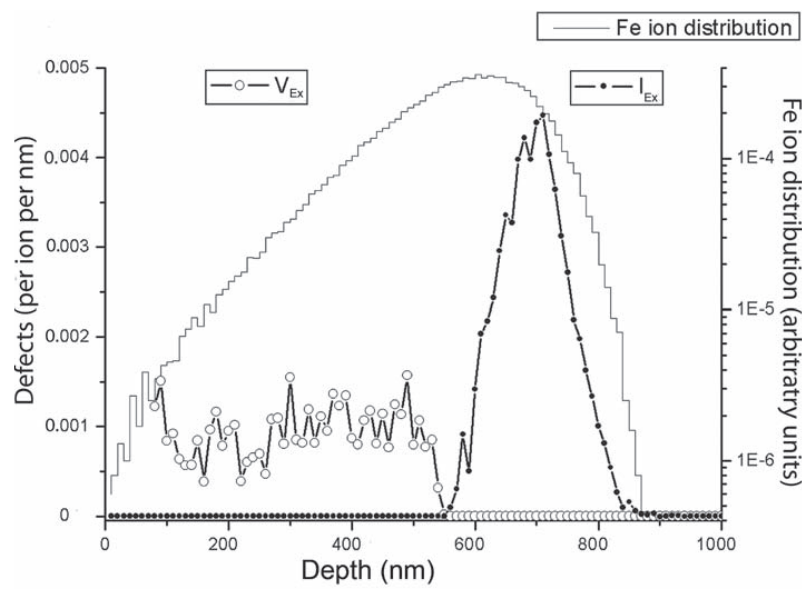

Fig. 3: Calculated depth profile for implantation of $2.5 \mathrm{MeV} \mathrm{Fe}^{+}$ions into ODS steel together with the corresponding distributions of excess vacancies $V_{E x}$ and excess interstitials $I_{E x}$. The ion beam hits the sample surface under an angle of $22.5^{\circ}$.

Extended SRIM calculations [Kögler et al. 2009] of the damage profile are given in Fig. 3 and show a maximum of the implanted $\mathrm{Fe}^{+}$ions at about $600 \mathrm{~nm}$. The full cascade of radiation damage was calculated and displayed in Fig. 3 with the produced excess interstitials and excess vacancies. The area of excess vacancies is spatially well separated from the excess interstitials and shows different features. The vacancy-rich region is fairly flat and located close to the surface ranging from up to 500 $\mathrm{nm}$. The excess interstitials appear at larger depth with a maximum around $700 \mathrm{~nm}$.

\subsection{Nanoindentation}

Ion implantation as a convenient way for introducing irradiation damage has a limited damage depth, which is about $850 \mathrm{~nm}$ maximum in our experiments. Nanoindentation is a suitable method to determine the mechanical properties of such a thin irradiated surface layer. During a typical nanoindentation test, load and displacement are recorded as the indenter tip is pressed into the sample surface with a prescribed loading and unloading profile. The load-displacement curve provides much more information than a microscopy image of the impression, since it includes plastic and elastic features of the material. The main reason for the application of nanoindentation is its relative experimental simplicity with minimal specimen preparation required. In contrast to other established mechanical tests, e. g. uniaxial tension, the goal of indentation experiments is to probe small volumes and to perform indentations on submicron scales [Gouldstone et al. 2007, Wolf et al. 2003, Richter et al. 2008, Chen et al. 2010]. Additionally, the technique has a great importance for 
experimental studies of fundamental material physics on the basis of high resolution load-displacement data.

Most nanoindentation experiments were performed using the electrostatic transducer of the Hysitron triboscope in the UBI 1 at the Technical University of Applied Sciences Wildau. The maximum load applied is $10 \mathrm{mN}$. Most indents were performed at lower load to study the near surface area in more detail and to avoid effects from the bulk non-irradiated material. In order to get a survey about the hardness profile with larger depth, indentation with the UNAT-M of the company ASMEC was performed up to $100 \mathrm{mN}$.

The most common use of nanoindentation is for the measurements of hardness and indentation modulus. Hardness $\mathrm{H}$ represents the mean contact pressure under load and is obtained by the applied load F divided by the projected area $A_{c}$ of the indenter tip at the corresponding contact depth $h_{c}$. The indentation modulus $\mathrm{E}$ is derived from the slope of the load-displacement curve upon unloading as the material recovers elastically [Oliver et al. 1992, Wolf et al. 2003]. All load-displacement curves were analyzed according to the standard Oliver-Pharr method [Oliver et al. 1992]. Investigations are performed with a blunted $90^{\circ}$ diamond cube corner tip. The calibration of the tip to determine the depth dependent area function $A_{c}\left(h_{c}\right)$ was obtained with the standard curve-fitting method using fused quartz, with its known reduced modulus as the reference material. Additionally, calibration with a sharp silicon grating was performed [Richter et al. 2006].

\section{Results}

Typical microstructures of as-received PM2000 ODS steel are shown in Fig. 4a. A few dislocation lines are clearly visible. The fine-scale Y-Al-O particles tend to pin dislocations (Zener pining), which revealed evidence of particle-subgrain boundary interactions in the microstructure. The high temperature strength of the ODS alloys emanates from the inhibition of dislocation motion in the metal matrix by the oxide dispersion retarding the recovery and re-crystallization processes. This increases the creep resistance of the alloys.

Fig. 4b shows the microstructures of an as-received PM2000 steel after dual beam irradiation. Transmission electron microscopy (TEM) observations have been performed at the cross section area on the top thin layer (about $850 \mathrm{~nm}$ depth), where irradiation damage was


Fig. 4: TEM micrographs of ODS PM2000 steel with (a) Y-Al-O particles pinning dislocations in the as-received state and (b) cross section micrograph after dual beam irradiation with bright spots indicating a band of He filled vacancies marked by red circles.

generated. A large number of bright spots was detected by over and under focus of the electron beam. The features marked by red circles on the TEM image (Fig. 4b) might represent helium filled vacancies, which are non-uniformly distributed in the microstructure. The size of these helium cavities is about $6 \mathrm{~nm}$ in diameter and they tend to form a vacancy band. In general, helium bubbles act as formation sites for growing voids and can also lead to highly brittle intergranular fast fracture as helium formed on grain boundaries [Odette et al. 2008]. 
Depth dependent hardness measurements of the ODS as-received samples are displayed in Fig. 5. These nanoindentation measurements confirm the hardness increase in the thin irradiated surface layer. Measurements with large applied loads up to $100 \mathrm{mN}$ were performed, which result in a penetration range that corresponds to the peak in the calculated average displacement damage (see Fig. 3). At about $600 \mathrm{~nm}$ depth, the hardness of the dual beam irradiated ODS alloy has the same value as that of the non-irradiated state. The measured hardness in this region was dominated by the large volume of softer non-irradiated material beyond the implanted range. There is pronounced pile-up around the nanoindents, but significant cracking could not be observed. The hardness close to the surface at $100 \mathrm{~nm}$ displacement is about $0.7 \mathrm{GPa}$ larger in the irradiated region compared to that in the non-irradiated sample. The hardness decreases gradually with increasing displacement and finally approaches the hardness value of the non-irradiated bulk state.

Since hardness values at very shallow penetration depth cannot be obtained with high accuracy at large applied loads, measurements have been performed up to a depth of $250 \mathrm{~nm}$ with an applied maximum load of $5 \mathrm{mN}$. The results for ODS are shown in the insert of Fig. 5. For the non-irradiated ODS sample, the hardness decreases with increasing penetration depth from $5.15 \mathrm{GPa}$ in the near surface region to an almost constant value of $4.2 \mathrm{GPa}$ at about $250 \mathrm{~nm}$ in the bulk material. This hardness change is attributed to the well-known indentation size effect (ISE) [Nix et al. 1998, Wolf et al. 2003], which is also discussed in other nanoindentation studies of ion irradiated steels [Hosemann et al. 2008, Heintze et al. 2009, Pouchon et al. 2010].

The depth dependent hardness profile for the irradiated ODS sample is significantly different from that of the non-irradiated one and reflects the irradiation induced hardness changes in a thin surface layer. It is clearly seen that the dual beam irradiation causes a drastic increase of the hardness in comparison to that of the non-irradiated ODS sample. The ISE effect would not be strong enough to account for that hardness increase close to the sample surface. Thus, the dual beam irradiation is the main factor to generate such a typical depth dependent hardness profile. There is a clear hardness maximum of $6.3 \mathrm{GPa}$ at about $50 \mathrm{~nm}$ with a steady decrease to a close proximity of the hardness of the non-irradiated ODS sample. The hardness increase



Fig. 5: Depth dependent hardness of ODS in the as-received state ( non-irradiated) and after dual-beam irradiation ( $\Delta$ ) with $2,5 \mathrm{MeV}$ $\mathrm{Fe}^{+}$ions and $18 \mathrm{appm} / \mathrm{dpa} \mathrm{He}^{+}$. The insert displays the depth dependent hardness for smaller penetration values for $5 \mathrm{mN}$ maximum load.

in the irradiated sample is with $1.25 \mathrm{GPa}$ largest at the maximum hardness, which means $22 \%$ relative to the hardness in the non-irradiated ODS steel. For larger indentation depth, the hardness of the irradiated sample approaches that of the non-irradiated ODS steel. Although keeping in mind the 10\% Bückle rule [Bückle 1973], the measured hardness maximum is closer to the surface than expected from the maximum of the damage profile at $600 \mathrm{~nm}$ calculated by SRIM (Fig. 3). It could indicate that the hardness of the ODS material is not affected by the dual beam irradiation in the region where the most displacements per atom would be expected. However, the corresponding distributions of excess vacancy $\mathrm{V}_{\mathrm{Ex}}$ and excess interstitial $\mathrm{I}_{\mathrm{Ex}}$ could support an interpretation. The vacancy profile is located in a near surface region and is more or less flat up to a depth of $500 \mathrm{~nm}$, whereas the maximum of the interstitials is at $700 \mathrm{~nm}$. Dislocation loops may mainly form in the region of interstitials and cause a hardness increase beyond the maximum of the average damage profile of $\mathrm{Fe}^{+}$ions. Moreover, it is expected that the $\mathrm{He}^{+}$ions are very mobile in the irradiated iron matrix. They will not stay at the depth of their maximum defect deposition, but move to the vacancies where they accumulate and could form He bubbles. Therefore the number of defects in this region is increased. The dislocation loops as well as the He bubbles act as obstacles for the dislocation glide. Hence, the observed hardness maximum in a close surface region could be the result of additional formation of He cavities. Further experiments are in preparation to verify this interpretation. 


\section{Conclusions}

Based on this study on irradiation effects on mechanical properties in nanodispersed ODS steels the following conclusions have been reached.

- $\mathrm{Fe}^{+} / \mathrm{He}^{+}$dual beam ion irradiation method is one of the most suitable techniques to simulate real fusion environmental conditions and to study basic synergistic effects between the displacement damage and He implantation in ODS alloys.

- Nanoindentation is a useful tool to measure mechanical property changes in the damage layer of less than $1 \mu \mathrm{m}$ in ion irradiated nanodispersed ODS steels.

- Dual beam irradiation results in all PM2000 ODS samples in a hardening effect. For irradiated ODS steels, a distinct hardness maximum close to the surface is observed. This is in contrast to the depth, where the maximum average displacements per atom predicted by model calculations is expected. The irradiation induced hardness in the maximum was increased by $22 \%$ related to the non-irradiated ODS specimen.

- The full cascade of radiation damage was simulated by extended binary collision models. The area of excess vacancies is spatially well separated from the excess interstitials and shows different features. The shallow vacancy band close to the surface allows the accumulation of $\mathrm{He}^{+}$ions in the vacancies, thus forming fine He filled cavities. This model supports qualitatively the observed depth dependent hardening profile.

- Fine He cavities could be observed as bright spots of a few nanometers in TEM images of the irradiated ODS samples. They are not homogeneously distributed but form a band close to the sample surface. This supports the mechanism of He filled vacancies.

- These investigations help to understand the microstructural changes in PM 2000 Fe-based ODS alloys, which are considered as a prospective structural materials for high temperature gas cooled nuclear reactors.

- Further investigations are necessary to understand the role of the high dislocation density and the nanoparticles and their interaction with the irradiation produced defects.

\section{Acknowledgements}

We gratefully acknowledge financial support from Deutsche Forschungsgemeinschaft (DFG) under the grant RI 1093/10-1. We are pleased to acknowledge valuable discussions and support in TEM investigations with Prof. Gordon Tatlock, the University of Liverpool and Dr. Arndt Muecklich, FZD Rossendorf. The authors also thank Prof. Roger Smith, Loughborough University, for his permanent interest in this work and useful discussions, Dr. Bodo Wolf, the University of Applied Sciences Lausitz, for his support in nanoindentation and the team of the company ASMEC for providing some of the indentation measurements

\section{References}

Baluc, N. (2006): Materials for fusion power reactors, Plasma Phys. Control. Fusion 48 B165-B177.

Bückel, H. (1973): in The Science of Hardness Testing and its Research Applications, edited J.H. Westbrook and J. Conrad, ASM, Metals Park, Ohio.

Chen, C.-L., Richter, A., Thomson, R.C. (2010): Investigation of mechanical properties of intermetallic phases in multi-component Al-Si alloys using hot-stage nanoindentation, Intermetallics 18, 499-508

Duffy, D.M. (2010): Fusion power: A challenge for materials science, Phil. Transactions Roy. Soc. A 368, 3315-3328.

Gouldstone, A., Chollacoop, N., Dao, M., Li, J., Minor, A.M., Shen, Y.-L. (2007): Indentation across size scales and disciplines: Recent developments in experimentation and modeling, Acta Materialia 55, 4015-4039.

Guerin, Y., Was, G.S., Zinkle, S.J. (2009): Materials Challenges for Advanced Nuclear Energy Systems, MRS Bull 34, 10-14.

Heintze, C., Recknagel, C., Bergner, F., Hernández-Mayoral, M., Kolitsch, A. (2009): Ion-irradiation-induced damage of steels characterized by means of nanoindentation, Nuclear Instr. and Meth. B 267, 1505-1508.

Hosemann, P., Vieh, C., Greco, R.R., Kabra, S., Valdez,J.A., Cappiello, M.J., Maloy, S.A. (2009): Nanoindentation on ion irradiated steels, Journal of Nuclear Materials 389, 239-247.

Kaschny, J.R., Koegler, R., Tyrrof, H., Buerger, W., Eichhorn, F., Muecklich, A., Serre, C., Skorupa, W. (2005): Facility for simultaneous dual-beam ion implantation, Nucl. Instr. And Meth. A 551, 200-207.

Kishimoto, H., Yutani, K., Kasada, R. (2007): Heavy-ion irradiation effects on the morphology of complex oxide particles in oxide dispersion strengthened ferritic steels, Journal of Nuclear Materials $367,179-184$.

Kögler, R., Ou, X., Skorupa, W., Möller, W. (2008): The origin of the energy-dose window in separation-by-implanted-oxygen materials processing, Appl. Phys. Lett. 92, 181906-1-3.

Nix,W.D.,Gao, H. (1998): Indentation size effects in crystalline materials: A law for strain gradient plasticity, J. Mech. Phys. Solids 46, 411-425 
Odette, G.R., Alinger, M.J., Wirth, B.D. (2008): Recent developments in irradiation-resisitant steels, Annu. Rev. Mater. Res. 38, 471-503. Oliver, W.C., Pharr, G.M. (1992): An improved technique for determining hardness and elastic modulus using load and displacement sensing indentation experiments, J. Mater. Res. 7, 1564-1583.

Pouchon, M.A., Chen, J., Ghislemi, R., Michler, J (2010): Characterization of irradiation damage of ferritic ODS alloys with advanced micro-sample methods, Experimental Mechanics 50, 79-84.

Richter, A., Smith, R., Dubrovinskaia, N., Mcgee, E. (2006): Mechanical properties of superhard materials synthesised at various pressuretermperature conditions investigated by nanoindentation, High Pressure Research 26, 99-109.

Richter, A., Chen, C.-L., Smith, R., McGee, E., Thomson, R.C., Kenny, S.D. (2008): Hot Stage nanoindentation in multi-component Al-Ni-Si alloys: experiment and simulation, Journal Materials Science and Engineering A: Structural Materials: Properties, Microstructure and Processing 494, 367-379.

Wolf, B., Richter, A. (2003): The concept of differential hardness in depth sensing indentation, New Journal of Physics 5, 15.1-15.17.

Yamamoto, T., Odette, G.R., Miao, P., Hoelzer, D.T., Bentley, J., Hashimoto, N., Tanigawa, H, Kurtz, R.J. (2007): The transport and fate of Helium in nanostructured ferritic alloys at fusion relevant $\mathrm{He} /$ dpa ratios and dpa rates, J. Nucl. Mater. 367-370, 399-400.

Zinkle, S.J., Ghoniem, N.M. (2000): Operating temperature windows for fusion reactor structural materials, Fusion Engineering and Design 51-52, 55-71.

\section{Authors}

Prof. Dr. Asta Richter

Department of Engineering

University of Applied Sciences Wildau

asta.richter@th-wildau.de

\section{Ass.-Prof. Dr. Chun-Liang Chen}

Department of Materials Science and Engineering I-Shou University

Kaohsiung 840, Taiwan

\section{Dr. Reinhard Kögler and Dr. Georg Talut}

Institute of Ion Beam Physics and Materials Research Research Center, Dresden-Rossendorf FZD

01328 Dresden, Germany 